\title{
Balanço perguntado: o caso da segunda aposentadoria
}

José Roberto Kassai

Doutorado em Contabilidade pela Universidade de São Paulo - USP Av. Prof. Luciano Gualberto, 908, Cidade Universitária, São Paulo/SP. CEP:

05.508.900

E-mail: jrkassai@usp.br

\section{RESUMO}

Balanço perguntado representa um conjunto de técnicas que permite elaborar e analisar relatórios contábeis de pequenas empresas, tendo em vista que a maioria delas não dispõe de demonstrações contábeis adequadas. Ao longo de uma série de artigos publicados nos anais deste Congresso, no período de 2000 a 2004, foram abordados diversos temas sobre essa terminologia, curiosamente, pode-se notar que essas técnicas podem ser aplicadas perfeitamente sobre o universo das grandes empresas e o nível de sofisticação e complexidade desses conceitos também é crescente. Esse fato fez vir à tona um questionamento sobre a originalidade e a importância dessas contribuições atribuídas às pequenas empresas e, sob este pretexto, este trabalho tem por objetivo testar os conceitos implícitos nesses modelos em um caso real e de dimensões bem reduzidas, um micro- negócio informal. Desse modo, espera-se poder validar ou aprimorar essas contribuições para esse segmento tão significativo para as economias de todos os bairros e cidades deste mundo.

Palavras-chave: Balanço perguntado. Microempresa. Continuidade. Informalidade.

\section{Balance Inquired: the case of second retirement}

\section{ABSTRACT}

Balance inquired represents a set of techniques to elaborate and analyze financial reports of small companies, in view of the fact that most of them do not have adequate financial statements. A series of articles published in the annals of this Congress between 2000 and 2004 addressed different subjects about this terminology. It is remarkable that these techniques can perfectly be applied to the universe of large companies. These concepts also present rising sophistication and complexity levels. This fact gave rise to inquiries about the originality and importance of these contributions attributed to small companies. In this context, this study aimed to test the concepts implied in these models to a real case of small dimensions, i.e. an informal microbusiness. We hope to be able to validate or improve these contributions for such a significant economic segment around the world.

Key words: Balance inquired. Micro-company. Going concern. Informality. 


\section{INTRODUÇÃO}

A terminologia Balanço Perguntado tem sido utilizada nesses últimos anos para expressar uma técnica antiga adotada pelos analistas financeiros e que permite elaborar relatórios contábeis de pequenas empresas. Essa prática, como relata Kassai (2004), é baseada no modelo mental das demonstrações contábeis, mais precisamente sobre o balanço patrimonial e a demonstração do resultado de um exercício e consiste, basicamente, em um processo de entrevista entre o analista e o empreendedor e o que dá consistência e serve de roteiro nessa conversa é justamente a estrutura e lógica e natural existente nesses relatórios.

Para os profissionais que dominam a linguagem contábil, ou mesmo para aqueles que têm as noções básicas, pode parecer um modelo simples e um tanto óbvio, mas é nesse momento que se verifica um diferencial em relação aos demais profissionais. A visão patrimonial e sequencial das contas do ativo e do passivo permite a visualização global do empreendimento como investimento e suas formas de financiamentos. As contas da demonstração de resultado, em sua ordem lógica e dedutiva, servem de roteiro para o início de um orçamento. A combinação desses com a experiência gerencial das pessoas permite falar de negócios e de planejamento. E a lembrança de que o total do ativo tem que ser sempre igual o do passivo, proporciona segurança nas diversas simulações.

Nesses últimos anos foram publicados diversos artigos relativos a essa terminologia e, curiosamente, pode se notar que as técnicas que compõem esses modelos podem ser aplicadas tanto em pequenas como em grandes empresas, e o nível de complexidade e sofisticação também é crescente, o que faz vir à tona um questionamento sobre a originalidade dessas contribuições atribuídas às pequenas empresas. Seriam apenas simplificações do que já existe ou do que é aplicado nas grandes corporações? Qual a eficácia sobre as pequenas empresas? Esses conceitos e técnicas sofisticados estão condizentes com a realidade desses pequenos empreendimentos?

Orientados por esses questionamentos, e postergando-se para um outro momento uma discussão mais aprofundada do que verdadeiramente caracteriza uma pequena 
empresa, este trabalho tem por objetivo aplicar o modelo balanço perguntado em uma empresa de dimensões bem reduzidas, um micro-negócio informal, e, desse modo, validar ou aprimorar as contribuições para esse segmento tão significativo para as economias deste mundo.

Para isso, escolheu-se como estudo de caso um empreendimento real, a Cia. Aércio (nome fictício), e pretende-se acompanhar as principais etapas de processamento do balanço perguntado e refletir sobre os questionamentos acima. Preocupando-se em preservar a identidade do proprietário e seu negócio, algumas informações e valores foram ajustados, sem que isso prejudicasse o objeto desta pesquisa.

A validação do modelo perguntado será confirmada se o produto final resultar em relatórios adequados e que permitam análises razoáveis de desempenho econômico e financeiro.

Secundariamente, pretende-se selecionar uma lista de cinquenta conceitos básicos extraídos das principais publicações sobre esse modelo e, ao final, verificar quantos e quais deles foram aplicáveis e não aplicáveis e espera-se um índice de aplicabilidade superior a cinquenta por cento.

\section{SÉRIE BALANÇO PERGUNTADO E CNCEITOS APLICÁVEIS}

A terminologia balanço perguntado, como já foi comentada, refere-se a uma prática utilizada para viabilizar análises de relatórios contábeis de pequenas empresas, tendo em vista que a maioria delas não dispõe de demonstrações contábeis adequadas.

Apesar de ser uma prática antiga e adotada por diversas instituições de créditos, selecionou-se para fundamentar este trabalho um conjunto de publicações que contribuíram para ressaltar essa terminologia denominada por Kassai (2004) de "Série Balanço Perguntado", onde foram abordados os seguintes temas:

Sistemas de custos para pequenas empresas: experiência de uma editora.

Fluxo de caixa prospectivo: custos, preços e orçamento.

Pequenas empresas: como é difícil levantar dinheiro. 
Balanço Perguntado: solução para as pequenas empresas.

Termômetro de crédito: avaliação de propostas de créditos de pequenas empresas junto à Caixa Econômica Federal.

Custo de capital das pequenas empresas e escala hierárquica de risco setorial.

Balanço perguntado: casos práticos de pequenas empresas.

Balanço perguntado: uma técnica para se elaborar relatórios contábeis de pequenas empresas.

De uma lista de cem conceitos citados nesses trabalhos, foram selecionados cinquenta julgados relevantes para atender aos propósitos desta pesquisa e que servirão de referências na elaboração do balanço perguntado do caso real e nas reflexões das hipóteses levantadas. 


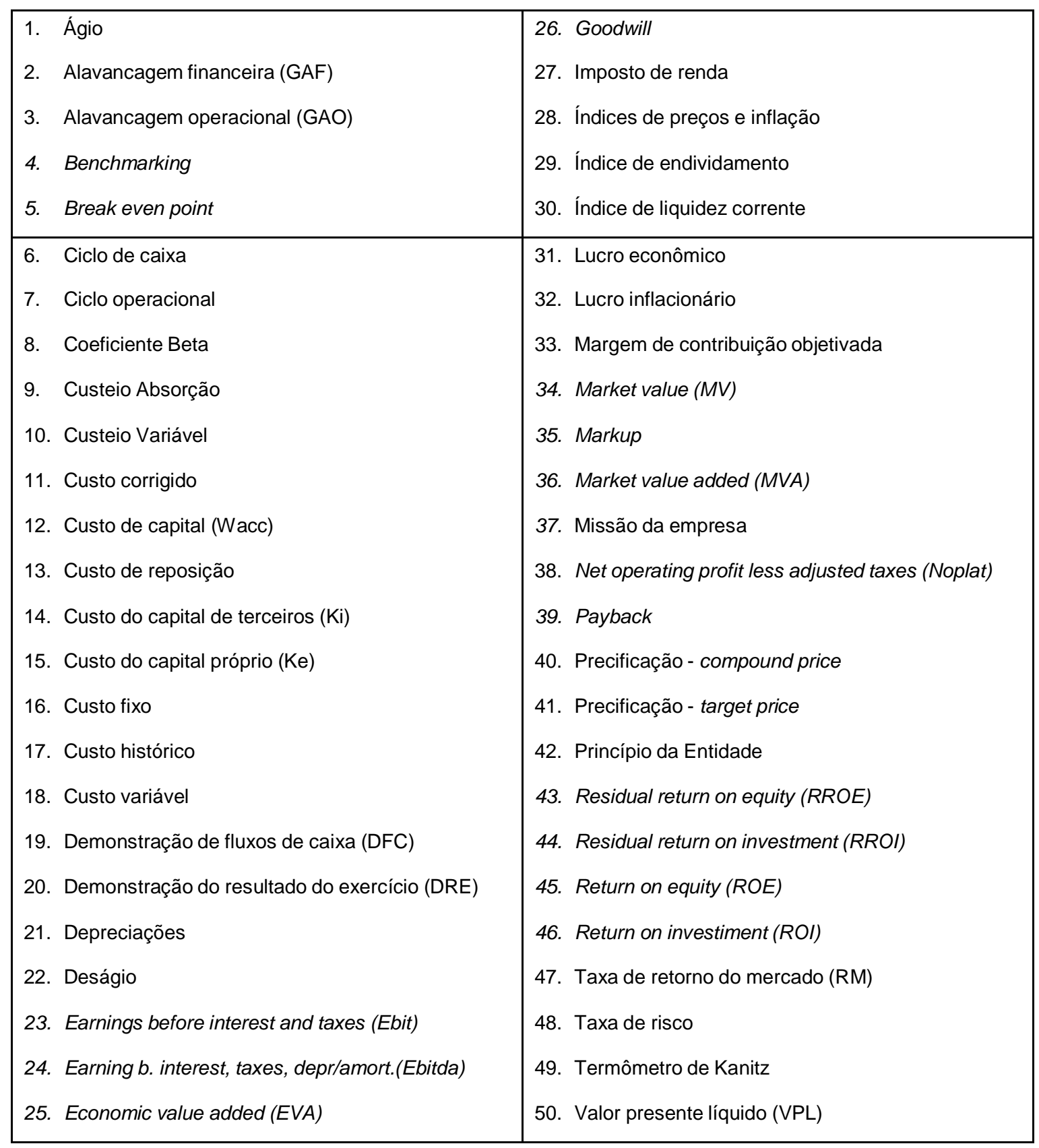

\section{O CASO REAL DA CIA AERCIO}

O caso da CIA AÉRCIO (nome fictício) refere-se a um empreendimento que já existe regularmente há mais de dez anos e, apenas por essa informação, pode-se inferir que se trata de um investimento sustentável. Um analista de balanços perguntados, muito provavelmente estaria ansioso por confirmar essa expectativa em 
suas análises finais e, mais do que isso, aprender e desvendar alguns de seus segredos.

É com esse espírito que o analista inicia o processo de balanço perguntado, com humildade e reconhecimento de que aquele empreendedor é possuidor de uma habilidade característica de poucos e que o diferencia da maioria das pessoas que prefere trabalhar com vínculo empregatício.

Nassif (1999, p. 4), em um de seus artigos publicados na Revista de Bordo da Varig, onde comenta a importância da fusão entre a Brahma e a Antártica para o capitalismo brasileiro, identifica dois personagens no cenário empresarial, a "pepita de maior valor" e a "pessoa com pouca imaginação", respectivamente o empreendedor e o gerente. A forma peculiar com que ele intitula esses personagens é, no mínimo, interessante e provoca muitas discussões sobre o que diferencia a maioria de nós (empregados) daquele empreendedor. Aliás, o leitor enquadra-se em qual dos personagens?

Nesse mesmo artigo, o jornalista comenta:

O empreendedor é pepita de maior valor, a pessoa que tem a intuição do momento, a visão estratégica, a identificação da oportunidade. Em geral, tem muita imaginação e visão do futuro. Só que, por suas próprias características, é pouco afeito à operação do dia-a-dia. Aí entra o complemento indispensável, o gerente, a pessoa com pouca imaginação, mas solidamente fincado no chão, incumbido de transformar as idéias em ação e em garantir o curto prazo da companhia.

Em verdade, a maioria das pessoas não saberia viver sem a segurança e o conforto de um salário no final de mês, das férias e do 13 salário, da cesta básica, do plano de saúde e de outros benefícios. Uma minoria sentir-se-ia confortável em iniciar um mês sem saber o quanto irá faturar, se sobrará bastante dinheiro no caixa ou se ao menos terá condições de pagar o aluguel, por exemplo.

O Sr. Aércio é um desses empreendedores e que faz parte dessa minoria. Está sempre com um sorriso no rosto, chama a todos de patrãozinho e distribui inúmeros "bom dia”, "boa tarde”, "como vai”. Atribui a si um honorário mensal de um salário mínimo 
(isso mesmo!) e orgulha-se de ter criado e instruído três filhos na faculdade, e sente-se feliz em lembrar que conseguiu levar sua esposa para conhecer a Grécia e países da Europa. Sua história pode ser vista na figura a seguir.

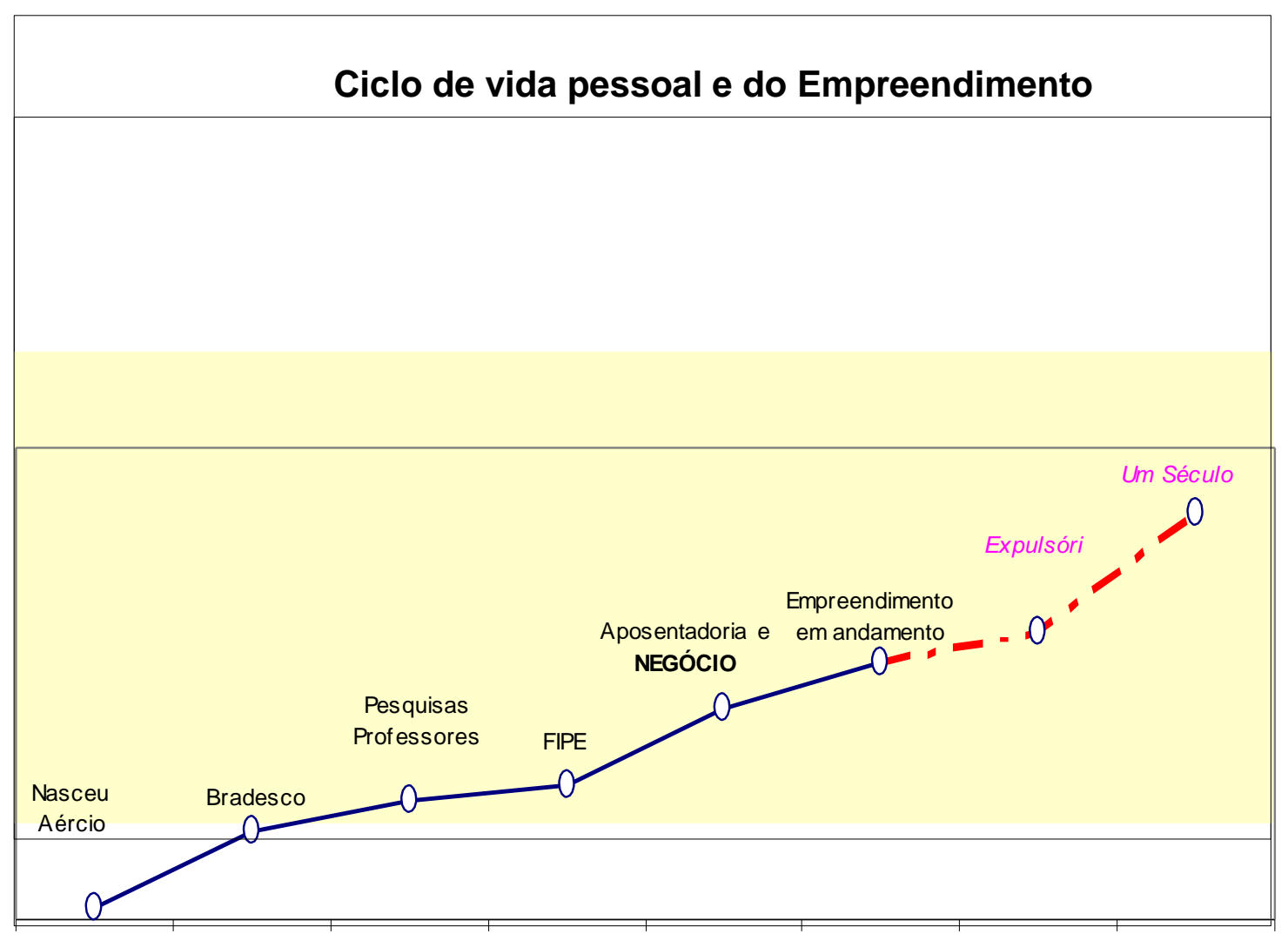


Os ciclos de vidas da pessoa do Sr. Aércio e de seu empreendimento estão bastante relacionados e o conjunto da missão, crenças e valores, bem como as metas e objetivos, muitas vezes se confundem. Nesses casos, tem-se a opinião de que essa situação é benéfica e a análise custo versus benefícios de uma eventual segregação das entidades seria inviável.

Nasceu em 1943 em uma cidade do interior de São Paulo e veio para a capital em 1962, para trabalhar no Bradesco onde aprendeu a digitar e perfurar cartões de computadores. Em 1970 começou a fazer alguns "bicos", auxiliando professores de uma faculdade de renome do país na perfuração de cartões e tabulação de suas pesquisas e, quando da iniciativa desses professores em criar uma fundação de pesquisas, em 1974, foi convidado a ser um dos membros fundadores e contratado como funcionário no ano seguinte, onde trabalhou por 20 anos ininterruptos, até a sua aposentadoria.

Ao receber as indenizações da aposentadoria e, diante das alternativas possíveis, não teve dúvida, resolveu abrir um negócio. Começou a fazer compras no Paraguai e revender os produtos à comunidade daquela faculdade, atendendo em torno de quatro mil pessoas entre professores, funcionários e alunos. Para realizar essa atividade, adquiriu um veículo Belina 1982 que serve para estocagem e exposição das mercadorias.

Ao ser questionado sobre o motivo que o levou a tomar a decisão de abrir esse negócio, o Sr. Aércio foi categórico: "a poupança não dá nada, qualquer coisa daria mais! ".

Tendo ou não conhecimento das teorias de finanças e das decisões de investimentos, o Sr. Aércio acabara de eliminar alguns dos cinquenta principais conceitos implícitos no balanço perguntado e mencionados no item anterior.

Como custo de oportunidade dessa decisão, ele atribuiu o rendimento da caderneta de poupança e, como não utiliza capital de terceiros (Ki), o custo médio ponderado de capitais (Wacc) corresponde ao custo de seu capital próprio (Ke). Ao ser indagado sobre os componentes risco, coeficiente beta, risk free, retorno do mercado, capital asset pricing model etc., ele não soube precisar, mas tem convicção de que a 
sua decisão pelo empreendimento foi melhor do que ter deixado o dinheiro parado na caderneta de poupança. Isso poderá ser confirmado nos números apurados neste trabalho.

Neste ano de 2005, e após mais de dez anos de atividades, o seu empreendimento está maduro e em atividade plena, e diz que pretende continuar trabalhando muito além da "expulsória" (na linguagem das universidades públicas, os professores e funcionários são obrigados a se aposentarem ao completar setenta anos de idade; mesmo assim, alguns retornam e continuam ministrando aulas e orientando alunos).

O princípio contábil da continuidade, por vezes destacado como postulado ou verdade aceita como premissa, nesse caso é interpretado de forma diferente. Em nenhum momento da conversa o proprietário mostrou preocupações com a perpetuidade desse empreendimento para além de sua própria vida, informando que não há nenhum acordo formal que garanta a sua ocupação no espaço da Universidade e nenhuma garantia de que um concorrente se estabeleça, tudo é uma questão de confiança conquistada nessas décadas e, provavelmente, a vida desse empreendimento estaria limitada a de seu fundador.

Qual a missão desse empreendimento? Ao discutir a razão da própria existência dessa empresa ou os fundamentos de sua perpetuidade, ficou evidente uma forte associação com a vida ou missão particular de seu proprietário. E, aos 61 anos de idade, aposentado, com casa própria, bem casado, orgulhoso de seus filhos, em harmonia com a vida e com seus princípios éticos e religiosos, agradece a Deus e pede que possa continuar com essa vida por muitos e muitos anos, sendo útil à comunidade e atingindo os resultados financeiros almejados de seu empreendimento.

Essa inteligência e perspicácia do negócio fazem parte das características pessoais do dono e, sem a intenção de mudar ou questionar os seus pensamentos, nem de expor os seus segredos e pontos fracos, dois aspectos foram destacados nas discussões em torno de sua missão empresarial: plano médico e margem de lucro zero. 
A preocupação acentuada com o pagamento das mensalidades do plano médico foi um dos pontos que despertou a atenção, por ser a despesa de maior valor dos gastos mensais da família, equivalente aos rendimentos de sua aposentadoria e, nesses anos todos, foram pagas integralmente pelo empreendimento. Esse tem sido um termômetro para avaliação do sucesso de seu negócio e, como solução emergencial em um cenário desfavorável, ainda restaria como alternativa utilizar os serviços de saúde pública e viver dos rendimentos de sua aposentadoria.

Essa despesa pessoal, apesar de ser lançada na empresa mensalmente, em sua essência poderia ser interpretada como retirada de lucros. Para o Sr. Aércio representa o custo de seu capital, em valor e não em percentual, é a remuneração que o deixa satisfeito e, pessoalmente, representa uma segunda aposentadoria e, como ele mesmo diz, "conseguida com menor esforço do que a primeira! ".

Em relação aos preços praticados, o Sr. Aércio confidenciou que há muito tempo não faz compras com regularidade no Paraguai e que, atualmente, abastecese nos mercados da Vinte e Cinco de Março (lojas semelhantes às do Paraguai) e praticando os mesmos preços (benchmarking) de seus fornecedores, ou seja, adota como estratégia "margem de lucro zero"; os seus preços são os mesmos praticados nas lojas da Vinte e Cinco, Galeria Pagé, Santa Efigênia, Brás, José Paulino, Liberdade etc. Com essa política ele dificulta os agentes concorrentes e viabiliza os seus negócios por meio de descontos obtidos devidos a sua pessoa e por comprar tudo à vista.

Como se viu nesses comentários iniciais, o empreendimento do Sr. Aércio é um micro- negócio e informal, possui um único funcionário que é ele mesmo, é o fundador e cotista majoritário e, devido as suas habilidades e competências, ou talvez circunstância, exerce simultaneamente os papeis de "empreendedor" e "gerente". É responsável pelas decisões estratégicas e de investimentos e, ao mesmo tempo, pelas atividades rotineiras de compras, estocagem, vendas, marketing, pós-venda, planejamento, entre outros. Em relação a essa atuação solitária, disse em tom baixo: "não é bem assim, na verdade eu só faço o que a minha mulher manda! "; ele se orgulha de contar com a assessoria desse conselho fiscal. 
Apesar de ter sido pioneiro na venda de disquetes, CDs e acessórios para informática e de conviver no meio de professores, pesquisadores e consultores das áreas de economia, administração e de contabilidade, não utiliza computadores nem quaisquer instrumentos sofisticados de controle.

Por esses motivos e pelos propósitos deste trabalho, o empreendimento do Sr. Aércio foi escolhido para estudos e, após o processo de entrevista do balanço perguntado, que durou cerca de duas horas e meia, obteve-se as demonstrações contábeis e análises a seguir.

\section{BALANÇO PERGUNTADO DA CIA AERCIO E ANÁLISES}

O processo de entrevista do balanço perguntado não tem um tempo definido como padrão ou ideal, às vezes consegue-se bons resultados em apenas um encontro e, em outras, é necessário repetir a conversa ou solicitar informações complementares.

A conversa com o Sr. Aércio foi bastante produtiva e os resultados foram alcançados em apenas um encontro e isso se deve, provavelmente, a alguns fatores fortuitos e ambientais, como: o conhecimento prévio entre as pessoas, empatia existente entre o analista e o empreendedor, pequeno negócio e com logística simples e a intenção do empreendedor em expor a sua vida e experiências em prol dos jovens alunos e empreendedores.

Surpreendentemente, em alguns momentos da conversa, houve lágrimas e emoções e isso faz lembrar que não é apenas mais um personagem que está respondendo a uma série de perguntas sobre um empreendimento qualquer. É uma pessoa humana que traz consigo lembranças e experiências de sucessos e frustrações, e que está falando sobre uma parte significante de sua própria vida. Esses momentos são raros na vida de um empreendedor e eles sentem prazer em expor suas histórias.

Depois da entrevista, segue-se o processamento das informações, como a montagem dos relatórios e as análises de consistência e, como resultados finais, foram obtidas as seguintes demonstrações contábeis. 


\section{Balanço Perguntado da Cia AÉRCIO}

\begin{tabular}{|c|c|c|c|}
\hline \multicolumn{2}{|l|}{ Ativo } & \multicolumn{2}{|l|}{ Passivo } \\
\hline Circulante & & Circulante & \\
\hline Disponível & 2.100 & Cheque especial & - \\
\hline Contas a receber & 300 & & \\
\hline Estoques & 600 & & \\
\hline Imobilizado & & Patrimônio Líquido & \\
\hline Belina L 1984 & 4.000 & Capital & 5.000 \\
\hline & & Lucros retidos & 2.000 \\
\hline Total... & 7.000 & Total... & 7.000 \\
\hline
\end{tabular}

Os saldos apresentados no balanço perguntado da Cia. Aércio representam valores médios ou ideais e foram obtidos de acordo com seguinte a composição:

Disponível: o Sr. Aércio adota uma política de saldo mínimo equivalente a três meses de mensalidade do seu plano de saúde e de sua esposa e, segundo ele, isso Ihe traz tranquilidade, "tranquilidade não tem preço" disse ele.

Contas a receber: a maioria de suas vendas é efetuada a vista e o valor estimado foi obtido em função de valores médios nos últimos meses.

Estoques: é representado por brinquedos, presentes e materiais de escritórios que ficam alojados em seu almoxarifado ambulante (um veículo Belina) e foram avaliados pelo preço de reposição. Custo histórico, custo histórico corrigido, índices de inflação, etc., são desprezados por ele, disse que o que vale é o preço do dia.

Imobilizado: é um veículo Belina ano 1984, cotado pela tabela Fipe de junho de 2005. Segundo o Sr. Aércio ele possui um outro veículo e, apesar de ter sido adquirido com recursos da empresa, não faz parte do empreendimento. Isso representa as retiradas de lucros nesses anos de atividades.

Passivo Circulante: por crença própria não admite dívidas, nem o uso de cheque especial. Uso de capital de terceiros para alavancagem dos negócios não faz parte de suas crenças.

Capital: é o valor atualizado de seu investimento inicial correspondente ao financiamento do imobilizado e parte do capital de giro. Perguntado sobre qual o melhor índice para atualização do capital, ele foi enfático: "o índice da Fipe, né patrãozinho". 
Lucros retidos: foi obtido "por diferença" e representa a parcela de lucros que não foram distribuídas no passado. Considerando-se que ele está sendo remunerado adequadamente, esse saldo representa o valor agregado do empreendimento, é o próprio economic value added (EVA) acumulado nesses anos de atividade.

\begin{tabular}{|c|c|c|c|}
\hline & Mês & Ano & \% \\
\hline Faturamento & 3.600 & $\overline{43.200}$ & $100,0 \%$ \\
\hline (-) Custo variável & $(2.160)$ & $(25.920)$ & $-60,0 \%$ \\
\hline Margem & 1.440 & 17.280 & $40,0 \%$ \\
\hline (-) Plano de saúde & (700) & $(8.400)$ & $-19,4 \%$ \\
\hline (-) Salários & $(300)$ & $(3.600)$ & $-8,3 \%$ \\
\hline (-) Combust. e manutenção & (200) & $(2.400)$ & $-5,6 \%$ \\
\hline (+) Receita financeira & 126 & 1.512 & $3,5 \%$ \\
\hline (-) Depreciações & (67) & (804) & $-1,9 \%$ \\
\hline (-) Alimentação & (80) & $(960)$ & $-2,2 \%$ \\
\hline Lucro & 219 & 2.628 & $6,1 \%$ \\
\hline
\end{tabular}

Os saldos evidenciados na demonstração do resultado do exercício perguntada da Cia. Aércio, representam valores médios mensais e anualizados e foram obtidos da seguinte forma:

Faturamento: representa um valor de venda média diária de $\mathrm{R} \$ 180,00$ projetada para 20 dias de trabalho por mês.

Custo variável: foi calculado em função da política de desconto que é obtido regularmente junto aos seus fornecedores nas lojas da Vinte e Cinco de Março (lojas semelhantes as do Paraguai). Perguntado sobre os conceitos das formas de custeamento das vendas (Absorção, Variável, $A B C$ ) ele foi claro a responder que considera somente os custos variáveis como custo das vendas.

Margem de Contribuição: em virtude da política de seus fornecedores, representa o desconto obtido. Esse valor é conservador, tendo-se em vista que outras mercadorias comercializadas geram margens maiores, principalmente as vendas por encomenda. Como a margem de contribuição é de $40 \%$ em média, o seu markup é de 1,67 vezes. 
Plano de saúde: é o valor da despesa mensais com o plano de saúde do Sr. Aércio e de sua esposa e são elevados em função de suas idades. $O$ rendimento mensal de sua aposentadoria é equivalente a essa despesa.

Salários: o Sr. Aércio diz não ter salário, mas resolveu-se atribuir pelo menos um salário mínimo como remuneração de seus serviços.

Combustíveis e manutenção do veículo: é o valor estimado do consumo de gasolina e eventual manutenção de sua Belina ano 1984, por sinal muito bem cuidada, é uma "raridade".

Receita financeira: Representa o juro recebido sobre o saldo no disponível que está aplicado em uma caderneta de poupança e, como foi comentado, representa uma estratégia de tranquilidade para garantir alguns meses de pagamento do plano de saúde.

Depreciações: é o valor calculado tendo-se em vista uma vida útil de cinco anos de seu veículo Belina ano 1984. O que se observa é que esses veículos não perdem valor, são raridades pelo seu estado de conservação. A manutenção é econômica, não utiliza seguro há muito tempo e os consertos geralmente são efetuados por ele mesmo ou por seus muitos amigos. Na conversa inicial com o Sr. Aércio, ele disse que não se preocupava com essa despesa e que, a partir de agora, passaria a incluí- lá como parte de seu custo fixo.

Alimentação: é o valor estimado considerando-se algumas refeições no Restaurante da Faculdade onde exerce suas atividades e das marmitas que sua esposa Ihe prepara. Algumas vezes sua esposa Ihe faz companhia no restaurante da faculdade e, quando the perguntam, responde que o dia foi bom.

Lucro: o lucro é lucro! Segundo o Sr. Aércio e, por isso, as discussões sobre lucro líquido, lucro operacional, Ebitda, Ebit, Noplat, etc., foram em vão. Mas ressaltou a premissa de que, no longo prazo, lucro é caixa. 


\section{ANÁLISES DO BALANÇO PERGUNTADO}

O balanço patrimonial e a demonstração de resultado do exercício, obtidos pelo método balanço perguntado da Cia. Aércio, podem ser considerados adequados, pois apresentam consistência entre eles e permitem diversas análises econômicas e financeiras do empreendimento, a seguir.

Investimento total: como os valores dos ativos e passivos representam situações ideais, o total do ativo representa adequadamente o montante dos investimentos, não necessitando ajustes de passivos não-onerosos ou de eventuais ativos não aplicados na atividade operacional. Esse investimento é composto de capital de giro (43\%) e de capital fixo ou imobilizado (57\%).

Financiamento do investimento: como se pode ver, $100 \%$ do montante do investimento total é financiado por capital próprio e isso mostra uma realidade e característica das pequenas empresas que, em sua maioria, não dispõem de recursos de terceiros. Operações de desconto de duplicatas, hotmoney, contas garantidas, recebíveis e outras operações de custos "abusivos" não são considerados como capital de terceiros "sadios"; na bibliografia consultada sobre balanço perguntado, eles são reclassificados como despesas administrativas.

Break even point: considerando-se o custo fixo mensal de $R \$ 1.221,00$ e a margem de contribuição de $40 \%$, o ponto de equilíbrio mensal é de $\mathrm{R} \$ 3.053,00$ de faturamento ou uma média $R \$ 153,00$ por dia. Segundo o Sr. Aércio, esse valor é facilmente atingível e, quando atinge o ponto de equilíbrio no meio da semana, tira férias com sua esposa no restante dos dias.

Margem, Giro e Taxa de Retorno: a margem de lucro sobre as vendas é de $6,1 \%$ e o giro anual de seu investimento total é de 6,2 vezes e, segundo o empreendedor, esses resultados foram apurados de forma bem conservadora. $O$ produto entre essa margem e esse giro resulta em uma taxa de retorno de investimento de $37,5 \%$ ao ano. Em outras épocas o Sr. Aércio obteve margens e giros maiores, mas diz que hoje trabalha o mínimo necessário e sempre aproveitando as épocas festivas; é comum vê-lo vestido com a camisa da seleção brasileira, com 
chapéu de palha e camisa listrada, com fantasias de halloween, chapéu de papai noel etc.

Return on investiment ( $R O)$ : é calculado dividindo-se o lucro anual ( $R \$$ $2.628,00)$ pelo total do investimento da Cia.Aércio $(R \$ 7.000,00)$ e representa exatamente a taxa de retorno calculada no item anterior $(37,5 \%)$, pois se trata de um desdobramento algébrico da ponderação da margem sobre as vendas e do giro do investimento. Como se pode ver, é uma taxa de retorno invejável e supera quaisquer outras alternativas disponíveis no mercado financeiro.

Custo de capital e spread: segundo o próprio empreendedor, seu custo de oportunidade é equivalente ao rendimento da caderneta de poupança ( $6 \%$ ao ano) e, nesse caso, o residual return on investment (RROI) seria o spread entre a taxa de retorno de investimento $(\mathrm{ROI}=37,5 \%)$ menos o custo de capita próprio, resultando em $31,5 \%$.

Economic value added (EVA): lucro residual ou econômico, pode ser obtido multiplicando-se o montante do investimento $(R \$ 7.000,00)$ pelo residual return on investment $(R R O I=31,5 \%)$, resultado em $R \$ 2.208,00$ anuais.

Economic value added (EVA) contábil: esse valor também pode ser obtido e interpretado a partir do lucro contábil $(R \$ 2.628,00)$ menos a remuneração do capital próprio $(\mathrm{R} \$ 7.000,00 \times 6 \%=\mathrm{R} \$ 420,00)$.

Market value added (MVA): é o valor presente dos EVAs futuros, descontados pela taxa de custo de capital (6\%), resultando em $R \$ 36.800,00$. Essa é uma das formas de se medir a parcela intangível da empresa ou o goodwill e, como se vê, é um empreendimento que se compara às atividades que têm grande capacidade de agregar valor e, se tivesse suas ações negociadas em bolsa de valores, provavelmente estariam sendo negociadas na Association of Securities Dealer Automated Quotation (NASDAQ).

Valor da empresa (VE): somando-se o investimento inicial $(R \$ 7.000,00)$ com o potencial de lucro econômico futuro ou goodwill (MVA $=36.800,00)$, obtém o valor da empresa de $\mathrm{R} \$ 43.800,00$. A empresa vale mais do que custa e, ao perguntar esse valor ao Sr. Aércio, ele diz que tem fundamento, pois sempre acreditou que seu 
negócio vale pelo menos o valor de um bom carro zero quilômetro. Com esse valor daria para fazer uma boa pesquisa nas principais agências e marcas de automóveis da praça. Em outros cenários de margens e giros, bem como de custo de capital, esse valor é crescente.

Ciclo operacional: o prazo médio de renovação dos estoques (PMRE) é de 8 dias e tem coerência quando o Sr. Aércio diz que vai à Vinte e Cinco de Março de três a quatro vezes por mês. O prazo médio de recebimento das vendas (PMRV) é de 3 dias e, portanto, o ciclo operacional é de 11 dias. Isso significa que entre comprar, vender e receber transcrevem 11 dias.

Ciclo de caixa: o prazo médio de pagamento das compras (PMPC) é nulo ou zero, pois as compras são realizadas a vista e, nesse caso, o ciclo de caixa é desfavorável em 11 dias. Ao questionar o Sr. Aércio sobre essa deficiência, ele disse que não havia pensado no prazo de estocagem (8 dias), considerava apenas o prazo de recebimento ( 3 dias). Mas, mesmo assim, a margem de lucro ainda cobre esse financiamento interno.

A despesa com o plano médico lançada na demonstração do resultado do exercício, como comentado anteriormente, pode ser tratado como remuneração do capital próprio, dada a estratégia e crença particular da Cia. Aércio. Nesse caso, o desempenho econômico poderia ser visualizado da seguinte forma:

\section{DRE perguntada da Cia AÉRCIO}

\begin{tabular}{|lccr|}
\hline Faturamento & Mês & Ano & $\frac{\%}{40}$ \\
(-) Custo variável & $\mathbf{3 . 6 0 0}$ & $\mathbf{4 3 . 2 0 0}$ & $\mathbf{1 0 0 , 0 \%}$ \\
Margem & $(2.160)$ & $(25.920)$ & $-60,0 \%$ \\
(-) Custo fixo & $\mathbf{1 . 4 4 0}$ & $\mathbf{1 7 . 2 8 0}$ & $\mathbf{4 0 , 0 \%}$ \\
Lucro & $(521)$ & $(6.252)$ & $-14,5 \%$ \\
(-) Plano de saúde (Ke) & $\mathbf{9 1 9}$ & $\mathbf{1 1 . 0 2 8}$ & $25,5 \%$ \\
Lucro econômico(EVA) & $(700)$ & $(8.400)$ & $-19,4 \%$ \\
& $\mathbf{2 1 9}$ & $\mathbf{2 . 6 2 8}$ & $\mathbf{6 , 1 \%}$ \\
\hline
\end{tabular}

Como se observa, o lucro seria ainda maior $(R \$ 11.028,00)$ e representa uma nova taxa de retorno de investimento $(\mathrm{ROI}=158 \%$ ao ano) absurdamente elevada, confirmando as expectativas do Sr. Aércio quando decidiu investir o dinheiro de sua aposentadoria nessa empresa. 
Essa e outras simulações poderiam gerar muitas outras análises e, como não é o objeto principal dessa pesquisa, faz-se agora alguns comentários dos outros conceitos mencionados na lista do item 2 deste trabalho e que não foram discutidos nas análises anteriores:

Ágio e deságio: o Sr. Aércio tem uma visão clara do que é um ágio ou um deságio e identifica esse "valor", por exemplo, quando compra suas mercadorias com desconto; mesmo avaliando o seu estoque a preços de reposição, também faz algumas contas pelo preço de venda.

Alavancagem financeira (GAF): não aplicável em seu empreendimento, além de evitar dívidas, não compreende os aspectos de alavancagem financeira.

Alavancagem operacional (GAO): como as margens e níveis de vendas foram considerados de forma conservadora, há espaço para otimizar o uso da estrutura de custos fixos.

Demonstração de fluxos de caixa (DFC): não aplicável, mas pode ser implantado futuramente.

Índice de liquidez corrente: não aplicável, pois não tem dívidas, compra tudo a vista.

Lucro inflacionário: ao ser questionado sobre inflação, o Sr. Aércio disse que não existe mais, "os preços lá na Vinte e Cinco estão baixando!".

Ebitda, Ebit e Noplat: não aplicáveis em virtude da não utilização de capital de terceiros e, por isso, o lucro líquido tem os mesmos significados das outras medidas de lucros antes dos impostos, juros e depreciação (Ebitda), antes dos impostos e juros (Ebit) e lucro operacional antes dos juros (Noplat).

Compound price e target pricing: O Sr. Aércio adota o método target pricing para fazer seus preços de vendas, ou seja, tem como referencial o mercado da vinte e cinco de março. A precificação com base nos custos, impostos e margem (compound pricing) não é utilizada e margem de contribuição é objetivada.

Imposto de renda: não aplicável e pode-se inferir que não cabem discussões éticas sobre esse quesito.

Markup: não aplicável, pois faz preços por benchmarking; na verdade, a margem de contribuição de 40\% representa um fator multiplicativo de 1,67. 
Payback: o prazo de retorno é mínimo, inferior a um ano. A preocupação é com a continuidade e não com o retorno.

Termômetro de Kanitz: não aplicável, pois a estrutura da empresa é muito simples e o termômetro de insolvência de Kanitz considera empresas com dívidas; o cálculo desse índice seria sempre próximo a zero e sem significado. O Termômetro de crédito da Caixa Econômica Federal, citado em um dos trabalhos da série balanço perguntado, provavelmente teria uma indicação melhor.

Valor presente líquido (VPL): o Sr. Aércio adota a política de valor presente líquido próximo à zero no longo prazo, pois, apesar de ser o negócio altamente lucrativo, pratica os mesmos preços da Vinte e Cinco de Março e, no longo prazo, almeja retorno mínimo para lhe garantir a sua segunda aposentadoria. É oportuno expressar a opinião de que a longo prazo o valor presente líquido dos projetos tende a ser próximo a zero, pois os mercados se ajustam.

\section{CONSIDERAÇÕES FINAIS}

A validação dessa pesquisa foi estruturada em duas hipóteses que poderiam ser validadas com: (1) a elaboração do balanço perguntado de forma adequada; e (2) com a discussão e aplicação de mais da metade dos cinquenta conceitos listados no trabalho.

Como pode ser constatado, foi possível elaborar o balanço perguntado da Cia. Aércio e, apesar da simplicidade de suas demonstrações contábeis, pode-se notar consistência entre o balanço patrimonial, a demonstração de resultado do exercício e as análises econômicas e financeiras. O processo ocorreu de forma natural entrevista, processamento e análises - e não necessitou de grandes ajustes.

Da lista dos cinquenta conceitos selecionados e mencionados no item 2 deste trabalho, $72 \%$ deles foram aplicáveis e serviram de roteiro para as discussões e análises desenvolvidas. Isso mostra que mesmos os conceitos considerados como sofisticados, quando enfocados de forma simples e objetiva, são coerentes com a lógica do empreendedor e do empreendimento. 
Conceitos aplicados e discutidos (72\%): ágio, alavancagem operacional, benchmarking, break even point, ciclo de caixa, ciclo operacional, custeio Absorção, custeio variável, custo de reposição, Ke, custo fixo, custo variável, DRE, depreciações, EVA, goodwill, lucro econômico, margem de contribuição, market value ou valor da empresa, MVA, missão da empresa, target price, entidade, RROI, ROI, custo corrigido, Wacc, Ki, custo histórico, deságio, markup, RROE, ROE, VPL, Payback, compound price.

Conceitos não aplicáveis ou não discutidos (28\%): alavancagem financeira, beta, DFC, Ebit, Ebitda, IR, Inflação, endividamento, liquidez corrente, lucro inflacionário, Noplat, taxa de retorno do mercado, taxa de risco, Termômetro de Kanitz. Mesmo não tendo sido aplicados nesse caso, acredita-se que esses e outros conceitos mencionados nas publicações da série balanço perguntado podem ser aprimorados e aplicados às microempresas.

As duas hipóteses foram confirmadas e, com base na metodologia estruturada dessa pesquisa, pode-se validar a originalidade do método balanço perguntado como instrumento aplicável ao segmento de pequenas empresas, mesmo para aquelas microempresas e de mercados informais.

\section{REFERÊNCIAS}

AGUIAR, A.A.R. e J.R. KASSAI. 2004. Balanço perguntado: o caso da Cia P\&G. Monografia de graduação entregue. São Paulo, FEA/USP.

Faculdade de Economia, Administração e Contabilidade da Universidade de São Paulo. 2004. A FEA em números. São Paulo, FEA.

GREBNER, S. 2003. Análise do PROGER concedidos às pequenas empresas. São Paulo, SP. Dissertação de mestrado. FEA/USP.

JACINTHO, J.R. de M. 2002. Contribuição ao processo de avaliação de desempenho patrimonial, econômico e financeiro das microempresas e pequenas empresas. São Paulo, SP. Dissertação de mestrado. PUC/SP.

KASSAI, J.R. 1994. Fluxo de caixa prospectivo. Caderno Temática IOB. 
KASSAI, J.R. 2001. Aspectos observados na conciliação do valor presente líquido (VPL) com o economic value added (EVA). São Paulo, SP. Tese de doutorado. FEA/USP, 333 p.KASSAI, J.R. 2004.

Balanço perguntado: uma técnica para se elaborar relatórios de pequenas empresas. In: Congresso Brasileiro de Custos, 21, Porto Seguro, 2004. Anais.

KASSAI, J.R. e KASSAI, S. 2001. Balanço perguntado - solução para as pequenas empresas. In: Congresso Brasileiro de Custos, 8, São Leopoldo, 2001. Anais...

KASSAI, J.R. e KASSAI, S. 1998. Sistema de custos para pequenas empresas experiência de uma editora. In: Congresso Brasileiro de Custos, 4, Fortaleza, 1998. Anais...

KASSAI, J.R. e KASSAI, S. 2002. Termômetro de crédito - avaliação de propostas de créditos de pequenas empresas junto à Caixa Econômica Federal. In: Congresso Brasileiro de Custos, 19, São Paulo, 2002. Anais...

KASSAI, J.R.; KASSAI, S. e NAKAO, A.N. 2003. Custo de capital das pequenas empresas. In: Anais do XX Congresso Brasileiro de Custos, 20, Guarapari, 2003. Anais...

KASSAI, J.R.; KASSAI, S e NOSSA, V. 2000. Pequenas empresas - como é difícil levantar dinheiro. In: Congresso Brasileiro de Custos, 7, Recife, 2000. Anais...

KRAUSS, V.A. 2003. Aspectos de avaliação de empresas. São Paulo, SP. Dissertação de mestrado. FEA/USP.

MATIAS, A.B. e PONGELUPPE, P.K. 2003. O Balanço Perguntado e a Cadeia de Valor da Informação: instrumento essencial no processo de decisão de crédito a empresas de pequeno porte. In: Seminário de Informação Corporativa, 1, São Paulo, 2003. Anais... São Paulo, FEA/USP.

NAKAO, A.N. 2003. Escala hierárquica de risco setorial (EHRS) das pequenas empresas - um estudo de caso. São Paulo, SP. Dissertação de mestrado. FEA/USP, 134 p.

NASSIF, L. 1999. A era das fusões. Revista de Bordo da Varig.

ONISHI, L.H. 2003. Concessão de crédito no CEAGESP. São Paulo, SP. Monografia de graduação. FEA/USP.

Série Balanço Perguntado. Departamento de Contabilidade e Atuárias da FEA/USP, 2004. www.eac.fea.usp.br/eac/docentes/kassai/- 